NASA Technical Memorandum 100267

AIAA-88-0264

\title{
High Speed Propeller Performance and Noise Predictions at Takeoff/ Landing Conditions
}

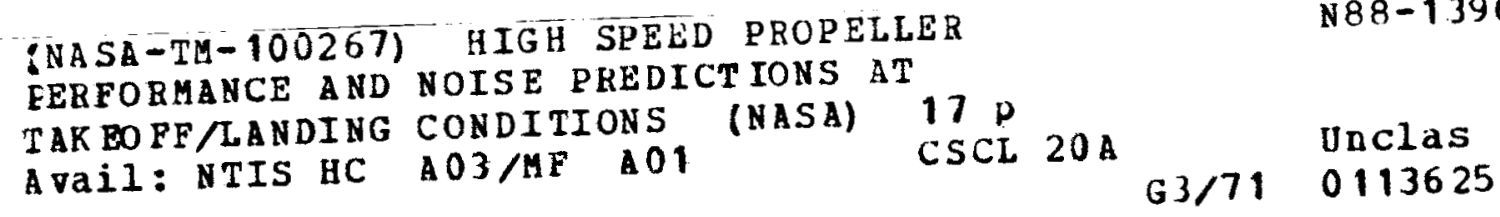

Sverdrup Technology, Inc.

Lewis Research Center

Cleveland, Ohio

and

R.P. Woodward and J.F. Groeneweg

Lewis Research Center

Cleveland, Ohio

Prepared for the

26th Aerospace Sciences Meeting

sponsored by the American Institute of Aeronautics and Astronautics

Reno, Nevada, January 11-14, 1988 
HIGH SPEED PROPELLER PERFORMANCE AND NOISE PREDICTIONS AT TAKEOFF/LANDING CONDITIONS

\author{
M. Nallasamy \\ Sverdrup Technology, Inc. \\ Lewis Research Center \\ Cleveland, Ohio 44135 \\ and \\ R.P. Woodward and J.F. Groeneweg \\ National Aeronautics and Space Administration \\ Lewis Research Center \\ Cleveland, Ohio 44135
}

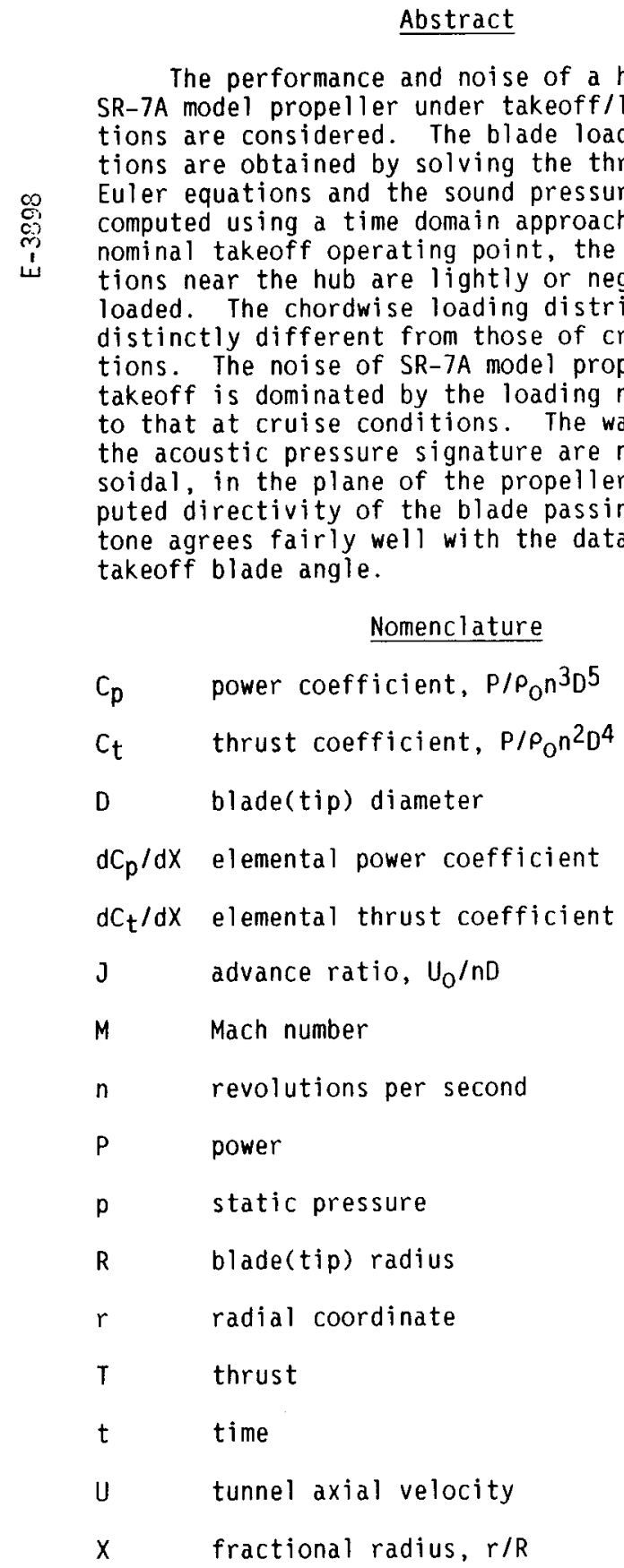

B blade angle at 75 percent radius

p density

$\theta \quad$ traverse angle

Subscript:

- free stream

\section{Introduction}

The advanced high speed turboprop is emerging as an efficient means of aircraft propulsion. The Propfan Test Assessment (PTA) flight program has validated the advanced propeller aircraft design features. Propfan aircraft, however, may produce considerable noise in the cabin as well as in the community. Installation effects can modify these noise levels. Propeller driven aircraft are known to produce more noise during takeoff than they would in level flight at the same operating point. The additional noise is attributed to the unsteady blade loading resulting from the angle of attack (of the propeller axis with the flow direction).

At takeoff conditions the main concern is the community noise. At zero angle of attack a noise level change is due to a change in blade setting angle or in the loading. The performance of the high speed (straight, SR-2 and swept, SR-3) pro peller models at takeoff, climb and landing regimes was studied by Stefko and Jeracki. 1 They tested the adjustable pitch models at Mach numbers $M_{O}$ $=0.1$ to 0.34 in the NASA Lewis $10^{\prime} \times 10^{\prime}$ supersonic wind tunnel. They generated detailed performance maps for takeoff, climb and landing conditions at zero angle of attack of the propeller axis with the flow direction. They found that the swept propeller had higher efficiencies than the straight one, in the regimes tested. This appears to be the only detailed performance data of advanced propellers available in these speed regimes.

Fujii et al.2 studied experimentally the aeroacoustics of advanced propellers at takeoff and landing conditions. They considered three configurations, backward swept blades, forward swept blades and alternately forward swept and backward swept blades. They evaluated both aspects of noise and performance. They found that, at small advance ratios $(0.4$ to 0.5$)$ the mixed configuration, al ternate forward-backward swept blade system gave the best results 
aerodynamically. The study of noise levels of the three configurations showed that the mixed configuration produced less noise than the only forward swept or only backward swept blades.

Recentiy, Woodward ${ }^{3}$ measured the sound pressure levels of a high speed propeller, SR-7A at simulated takeoff/landing conditions. The SR-7A has eight highly swept, highly loaded blades. He found that the tonal content of the SR-7A noise spectra was typically limited to the first three tone orders, with higher tone orders not present or masked by the broadband background noise probably associated with flow over the microphone. At zero angle of attack, he found that an increase in blade setting angle increased the peak noise level. He also investigated the effect of propeller angle of attack on noise level.

The present investigation is an attempt to predict the performance and noise characteristics of SR-7A model propeller at takeoff/landing conditions studied experimentally by Woodward. 3 Here, only zero degree angle of attack is considered. The performance calculations are done by solving the three-dimensional Euler equations. The computed blade pressures are used to compute the sound pressure level at any desired observer position, employing a time domain approach. For comparison with the measured acoustic data, the computed power level is scaled to the measured power level of each run.

\section{Performance and Noise Computations}

The blade loadings at takeoff conditions are obtained by solving the three-dimensional Euler equations employing the modified (for far-field boundary conditions) Denton computer program reported in Ref. 4. It was shown in Ref. 4 that the specification of nonreflecting far-field boundary conditions produced results which were in good agreement with experimental data at cruise conditions. Details of the flow field within the blade passage and the tip vortex were also found to be in qualitative agreement with probe/Laser Doppler Velocimetric (LDV) data.

Experimental data as well as the numerical predictions indicate a strong dependence of the total power coefficient of the propfan on the blade shape. It is difficult to determine the dynamic blade shape. An estimate of the untwist of the blade with centrifugal loading was available for the design, cruise conditions. This untwist was taken into account in the specification of blade angles in the numerical predictions reported in Ref. 4. Such an estimate of the untwist of the blade for the takeoff conditions is not available. The blade setting angles used in the present numerical predictions are the "design" coordinates of the blade. The blade shape change with centrifugal loading is not accounted for in the present calculations.

The blade pressures are obtained from the three-dimensional Euler solutions. The predicted variations of the total power coefficient with the blade setting angle and advance ratio are compared with data. The elemental power and thrust coefficients are also computed.

The sound pressure levels are computed employing the blade pressures obtained from the aerodynamic code, using Farassat's computer program for advanced propeller noise predictions, which employs a time domain approach. 5 This formulation is valid for both near and far field noise calculations and handles observers fixed to the ground frame or fixed to the aircraft frame. It uses two forms of the solution of the FfowcsWilliams and Hawking equation with thickness and loading source terms only. The subsonic or transonic solution is employed for the calculation depending on the radiation Mach number. Farassat's new formulation 6 was shown to predict the higher harmonics accurately. Since we are interested here only in lower harmonics (up to $3 \times B P F$ ) the formulation reported in Ref. 7 is used.

The program uses numerical integration techniques to compute the noise levels. The upper and lower surfaces of the blade are divided into panels The pressure distribution on these panels obtained from the Euler solution are used to calculate the acoustic pressure signature at any observer position. The contributions of all panels are added together to obtain the acoustic pressure signature. The signature for only one blade is calculated. The signature for several blades is obtained by shifting the signature for one blade in time and summing the pressures for each observer time within a period. The acoustic pressure signature is then fourier analyzed to obtain the noise spectrum. In the present computations, the sound pressure levels at eighteen axial locations are used to obtain a good definition of the directivity curve. The number of points computed for directivity is large enough to show the local maximum/minimum present, if any.

\section{Discussion of Results}

The configuration considered in the present study is the eight bladed SR-7A model propeller at takeoff condition, free stream Mach number $=0.2$. The acoustic calculations are carried out for a $1.68 \mathrm{~m}$ sideline corresponding to the experimental study of Woodward. 3 Figure 1 shows the SR-7A model propeller in the anechoic wind tunnel for acoustic tests. The NASA Lewis $9^{\prime} \times 15^{\prime}$ anechoic wind tunnel is located in the low speed return loop of the supersonic $8^{\prime} \times 6^{\prime}$ wind tunnel. Acoustic instrumentation in the $9^{\prime} \times 15^{\prime}$ tunnel consisted of fixed array microphones on the tunnel floor, near wall and ceiling and two microphones on the remotely controlled translating microphone probe. The translating microphone probe traversed $6.5 \mathrm{~m}$ of the acoustically treated test section of the tunnel. The data used for comparison with the predictions in the present paper are those obtained with the traverse microphone.

\section{Performance}

The blade pressure distributions of the SR-7A model propeller at takeoff conditions are computed by solving the three-dimensional Euler equations employing the modified Denton computer program. 4 The design characteristics of the SR-7A model propeller are shown in Table I. The nominal takeoff conditions are the following: the blade angle at 75 percent radius $=37.8^{\circ}$, free stream Mach number $=0.2$, and advance ratio $\left(U_{0} / \mathrm{nD}\right), J=0.89$. The computations were done for three blade angles and three advance ratios. The computed total power coefficients are compared with data in Fig. 2. 
The figure shows that the computed total power coefficient agrees fairly well with the wind tunnel data. The discrepancies observed may partly be due to the fact that the untwist of the blade under centrifugal loading is not considered in these computations.

The spanwise variations of the power coefficient are shown for three blade angles, namely, $32.0,37.8$ and $43.6^{\circ}$ in Fig. 3 . With increase in blade angle, the loading increases everywhere along the blade span. The peak in the elemental power coefficient occurs at about 85 percent blade radius for a blade angle of $43.6^{\circ}$. As the blade angle is decreased (total power decreased), the peak in the elemental power coefficient curve moves slightly inboard. For a blade angle of $32.0^{\circ}$, the peak in the elemental power coefficient occurs at about 82.5 percent radius. Such a movement of the peak in the elemental power coefficient with the blade angle was also found in the wind tunnel data of Stefko et al. 8

For the nominal takeoff blade angle of $37.8^{\circ}$ and free stream Mach number of 0.2 , the variations of the elemental power coefficient with advance ratio are shown in Fig. 4. The curves show the gradual increase in loading with decreasing advance ratio. The location of the peak in elemental power coefficient curve does not change for the range of advance ratios considered.

The variation of the elemental thrust coefficient with the blade angle are shown in Fig. 5 . The curves show a significant increase in the peak thrust coefficient with blade angle as observed in the experiments. 8 The dependence of the thrust coefficient on the advance ratio is shown in Fig. 6 . It is seen that the curves are smooth and show the expected variation along the span. At cruise conditions, 4 a "transition region" in the elemental thrust curve (corresponding to the blade shape transition) was observed in the case of SR-3 model propeller. It is interesting to note that such a "transition region" is absent in Figs. 5 and 6.

\section{Sound Pressure Levels}

The acoustic calculations employ the blade pressures obtained from Euler solutions. The sound pressure levels are computed employing the time domain approach of Farassat and his code for advanced high speed propeller noise predictions. 7 The typical blade loadings that are used in these calculations are shown in Figs. 7 and 8 . The chordwise loading distribution at three spanwise stations, namely, 21, 53, and 84 percent span are shown in Fig. 7. At 21 percent span, the low blade loading is clearly shown with a short chord length having a very low or negative loading. Such a low loading was not observed at cruise conditions. Another noticeable difference in chordwise loading distribution at takeoff conditions is the absence of the peak in the loading near the trailing edge. Such peaks at cruise conditions are associated with the trailing edge shock system. Because of the low Mach number flow at takeoff, no trailing edge shock system exists and thus no peak in the chordwise loading near the trailing edge is expected or observed. Figure 8 shows the spanwise loading distribution. This is similar to the blade loading obtained at cruise conditions, 9 except that the blade sections near the root are lightly loaded and the peak occurs away from the blade tip.
Because of the difference in loading distributions of takeoff and cruise conditions, it is instructive to examine the magnitudes of the noise components at takeoff. Figure 9 shows the directivities of the loading and thickness noise components and the total noise for the nominal takeoff conditions. First, we note that the noise under takeoff conditions is dominated by the loading noise. Secondly, the loading noise directivity does not show a local minimum in the plane of rotation of the propeller as observed in the cruise conditions. 9 The peak in the total noise directivity occurs aft of the plane of rotation of the propeller as in the cruise conditions.9,10 The appearance of the total noise peak aft of the propeller in the computed sound pressure levels is associated with the nature of the blade sweep and thus the same trend is seen at takeoff and cruise conditions.

\section{Directivities and Waveforms}

The predicted directivities of the blade passing frequency, second and third harmonics are shown in $\mathrm{Figs} .10(\mathrm{a})$ to $(\mathrm{c})$, for blade setting angles of $32.0,37.8$ and $43.6^{\circ}$ respectively, at the nominal takeoff advance ratio of 0.89 . The predicted sound pressure levels have been scaled to account for the overprediction of power by aerodynamic computations ( $F i g .2)$. Also shown in these figures are the wind tunnel data ${ }^{3}$ for comparison. For the blade angles considered, the peak in the BPF tone noise occurs aft of the plane of rotation of the propeller as observed in the wind tunnel data. The predicted BPF directivity agrees well with the data for the blade angle of $32.0^{\circ}$. At higher blade angles discrepancies between the prediction and data are observed. The maximum discrepancy in the predicted peak noise occurs at $43.6^{\circ}$ and is about $5 \mathrm{~dB}$. The peak levels of the second harmonics are fairly well predicted.

The increasing discrepancy of the predicted noise levels with increasing blade angle is attributed to the leading edge vortex and the tip vortex effects, which are not taken into account in the present computations. The existence of the leading edge vortex was shown clearly in Refs. 11 and 12 . As the blade angle increases, the strength of the leading edge vortex increases. Accounting for the leading edge vortex and in particular the variation of the vortex strength with the blade angle would improve the agreement of the predictions with data. Hanson 19 has found that accounting for the change in loading due to the leading edge/tip vortex alone would not improve the predictions significantly. He found that the inclusion of the radial forces due to the leading edge/ tip vortex as additional noise sources would improve the predictions.

Figure 11 shows the predicted and measured waveforms of the acoustic pressure signal in the plane of the propeller at the three blade angles. The waveforms were measured by the fixed microphone located at $0.95 \mathrm{~m}$ from the axis of the propeller. The distance correction has been applied to the data for comparisons with the predictions at $1.68 \mathrm{~m}$ side line. Typical waveforms averaged

I 400 revolutions and over eight blades have been chosen for comparison. The waveforms are nearly sinusoidal. At high blade angles, the value at the negative peak is higher than that at 
the positive peak. The measured trend of an increase in the difference in peak values with the blade angle is correctly predicted.

The peak noise level was observed to occur aft of the plane of rotation of the propeller (Fig. 10). The variation of the peak noise level with the blade setting angle is shown in Fig. 12 . The discrepancy between the prediction and data may be significantly reduced if the radial forces produced by the leading edge vortex are considered as additional noise sources.l

At the nominal takeoff blade angle of $37.8^{\circ}$, the effect of advance ratio on the noise level are shown in Figs. 10(b) and $13(a)$ and (b), which show the directivities of the BPF and harmonics. The predicted BPF tone levels agree fairly well with data in all the three cases. Figure 14 shows the waveforms in the plane of the propeller (BPF corresponding to each $J$ is indicated on the figure). The waveforms are nearly sinusoidal at a high advance ratio. As the advance ratio is reduced, the difference between the values at the positive and negative peaks increase significantly. The large variations in the peak noise level with advance ratio are consistant with the computed BPF tone levels. The effect of advance ratio on the peak noise is summarized in Fig. 15 . The figure shows that with increasing advance ratio (or decreasing rotational speed) the agreement of the predicted peak noise with data is improved.

It appears that the existence of the leading edge vortex and its interaction with the tip vortex are the major reasons for the discrepancy between the prediction and data. 11,12 Fine grid solutions of the Euler equations of the flow through the SR-7A model propeller show the existence of a leading edge vortex. The details of the leading edge vortex and its interaction with the tip vortex are being investigated.

\section{Concluding Remarks}

The three-dimensional Euler solutions of the SR-7A model propeller flow at takeoff conditions predict the total power coefficients which are in agreement with wind tunnel data. Detailed blade loading distribution data are unavailable for comparison. The sound pressure levels have been computed using a time domain approach. The predicted peak noise level is $2.5 \mathrm{~dB}$ lower than the measured value at the nominal takeoff blade angle. At higher blade angles, however, the discrepancy between the prediction and data increases. The increased discrepancy is probably due to the increase of the strength of the leading edge vortex with blade angle. Although the existence of the leading edge vortex is evident from the Euler solutions of the flow field and the oil flow visualization studies, a more detailed analysis is required to evaluate the influence of the leading edge vortex on the propeller performance and noise.

\section{References}

1. Stefko, G.L. and Jeracki, R.J., "Wind Tunnel Results of Advanced High Speed Propellers in the Takeoff, $\mathrm{Climb}$ and Landing Operating Regimes," AIAA Paper 85-1259, July 1985. (NASA TM-87054).

2. Fujii, S., Nishiwaki, H., and Takeda, K., "Aeroacoustics of an Advanced Propeller Design Under Takeoff and Landing Conditions," Journal of Aircraft, Vol. 23, No. 2, Feb. 1986, pp. 136-141.

3. Woodward, R.P., "Measured Noise of a Scale Model High Speed Propeller at Simulated Takeoff/Approach Conditions," AIAA Paper 87-0526, Jan. 1987. (NASA TM-88920).

4. Nallasamy, M., Clark, B.J., and Groeneweg, J.F., "Euler Analys is of the Three-Dimensional Flow Field of a High Speed Propeller: Boundary Condition Effects," Journal of Turbomachinery, Vol. 109, No. 3, July 1987, pp. 332-339.

5. Farassat, F., "Advanced Theoretical Treatment of Propelier Noise," Propeller Performance and Noise, VKI-LS-1982-08-VOL-1, Von Karman Institute of Fluid Dynamics, Belgium, 1982.

6. Farassat, F., "Prediction of Advanced Prope1ler Noise in the Time Domain," AIAA Journal, Vol. 24, No. 4, Apr. 1986, pp. 578-584.

7. Nystrom, P.A. and Farassat, F., "A Numerical Technique for Calculation of the Noise of High Speed Propellers With Advanced Blade Geometry, NASA-TP-1662, 1981.

8. Stefko, G.L., Rose, G.E., and Podboy, G.G., "Wind Tunnel Performance Results of a Aeroelastically Scaled $2 / 9$ Model of the PTA Flight Test Prop-Fan," AIAA Paper 87-1893, June 1987. (NASA TM-89917).

9. Nallasamy, M., Clark, B.J., and Groeneweg, J.F., "High-Speed Propeller Noise Predictions Effects of Boundary Conditions Used in Blade Loading Calculations," AIAA Paper 87-0525, Jan. 1987. (NASA TM-88913).

10. Brooks, B.M., "Analysis of Jetstar Propfan Acoustic Flight Test Data," Hamilton Standard, HSER-8882, 1983.

11. Hanson, D.B., "Propeller Noise Caused by Blade Tip Radial Forces," AIAA Paper 86-1892, July 1986.

12. Vaczy, C.M. and McCormic, D.C., "A Study of Leading Edge Vortex and Tip Vortex on Propfan Blades," Journal of Turbomachinery, Vol. 109, No. 3 , July 1987, pp. 325-331 
ORIGINAL PAGE IS

OF POOR QUALITY,

TABLE I. - SR-7A MODEL PROPELLER DESIGN CHARACTERISTICS

Diameter, cm (in.) . . . . . . . 62.2(24.5)

Number of blades . . . . . . . . . . . . 8

Design Mach number . . . . . . . . . . . . 0.8

Design tip speed, $\mathrm{m} / \mathrm{sec}(\mathrm{ft} / \mathrm{sec})$. . . . $244(800)$

Design advance ratio . . . . . . . . . . 3.06

Design power coefficient . . . . . . . . . . 1.45

Design power loading, $\mathrm{kW} / \mathrm{m}(\mathrm{hp} / \mathrm{ft})$. . . 257 (32.0)

Integrated design lift coefficient . . . . . 0.202

Activity factor . . . . . . . . . . . . . . 227

Design efficiency, percent . . . . . . . . . . 79

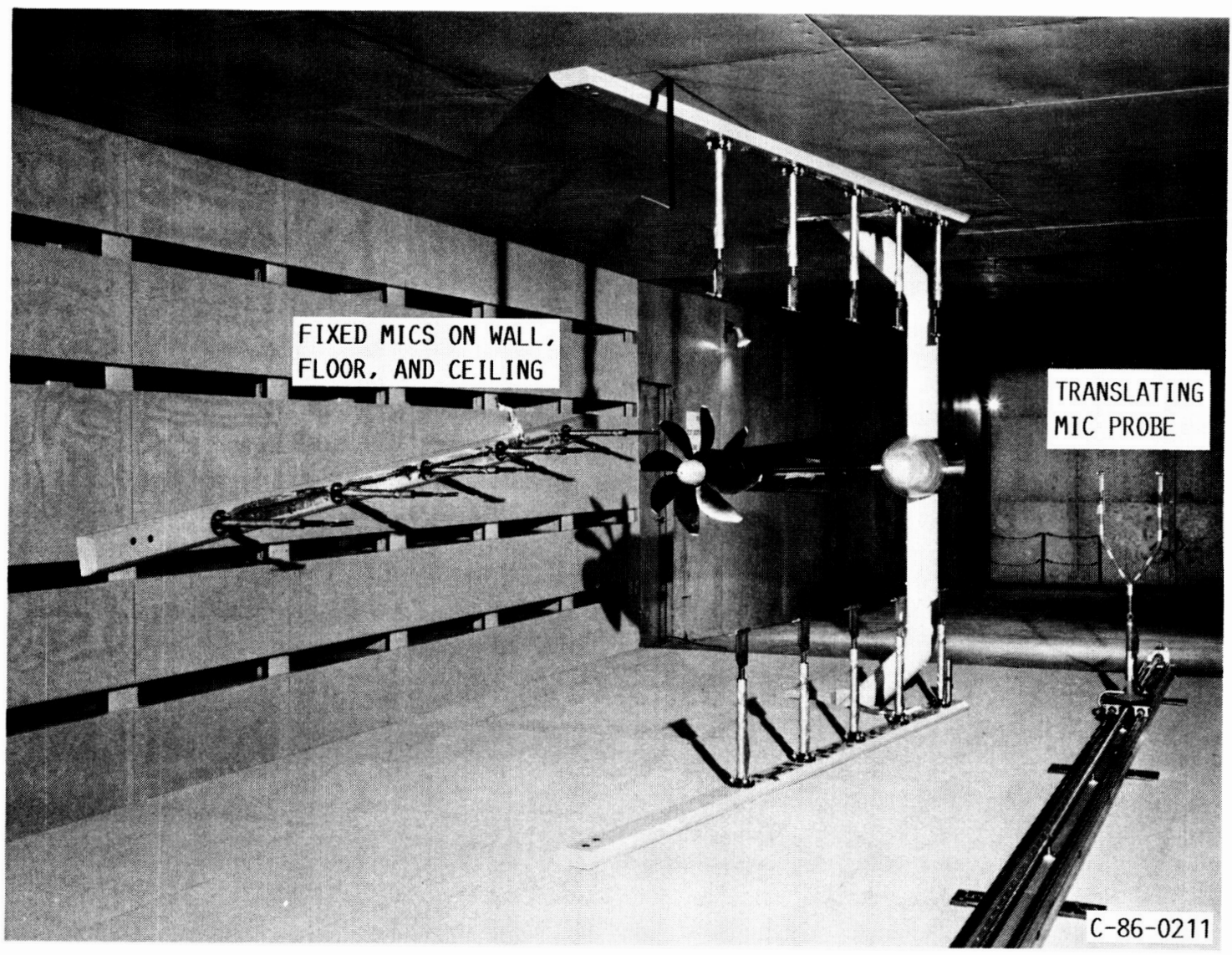

FIGURE 1. - PHOTO OF SR-7A MODEL PROPELLER IN THE ANECHOIC WIND TUNNEL. 


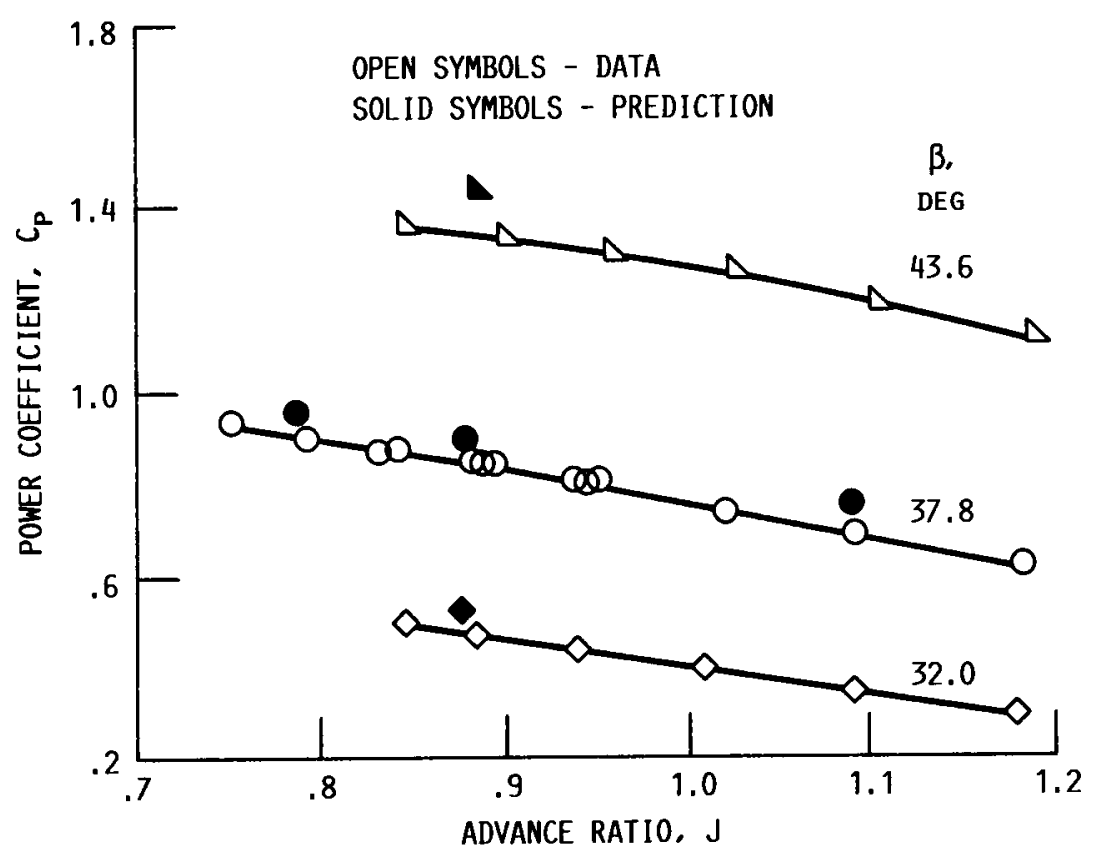

FIGURE 2. - COMPUTED AND MEASURED POWER COEFFICIENTS,

$M_{0}=0.2$.

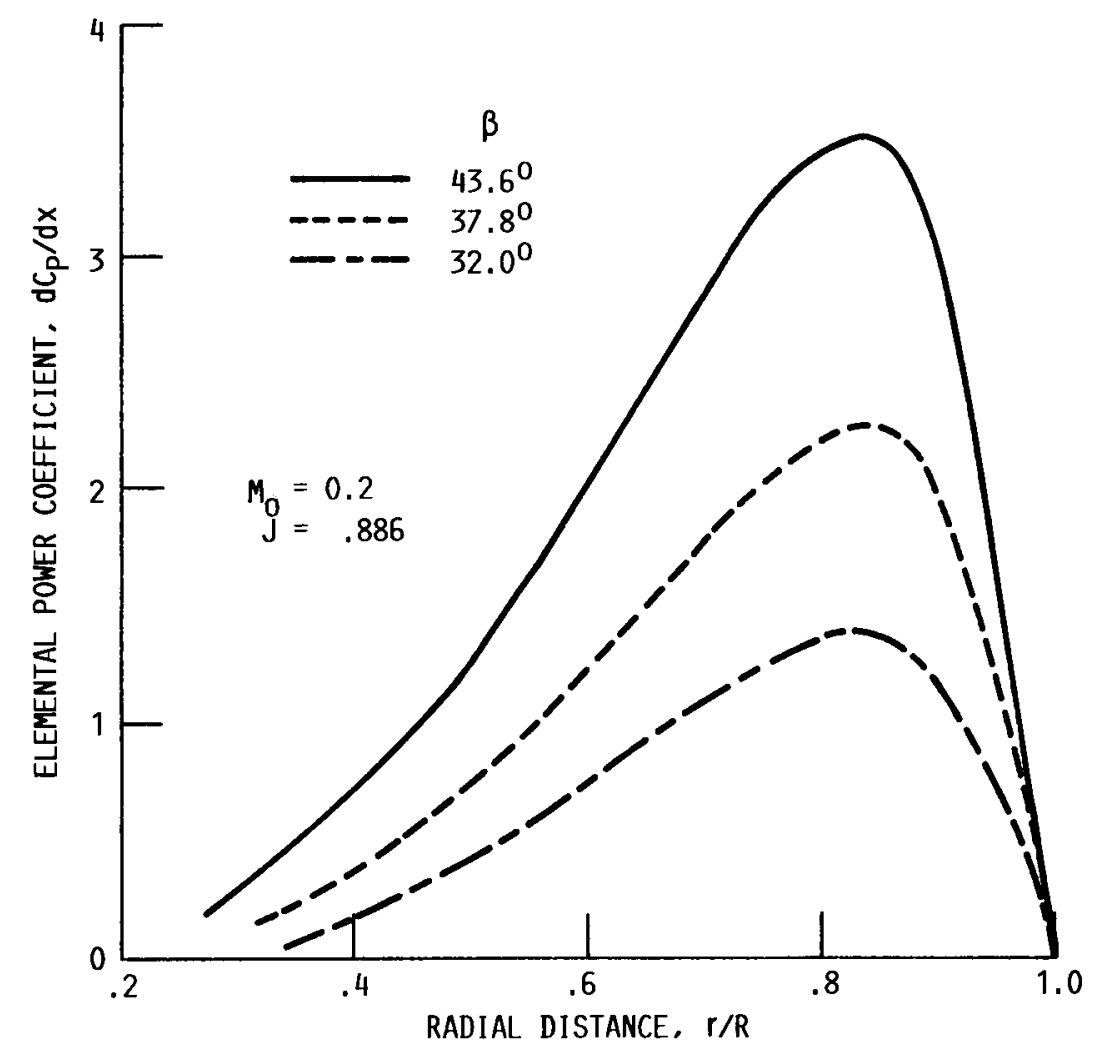

FIGURE 3. - ELEMENTAL POWER COEFFICIENT VARIATION WITH RADIAL DISTANCE AT THREE BLADE ANGLES. 


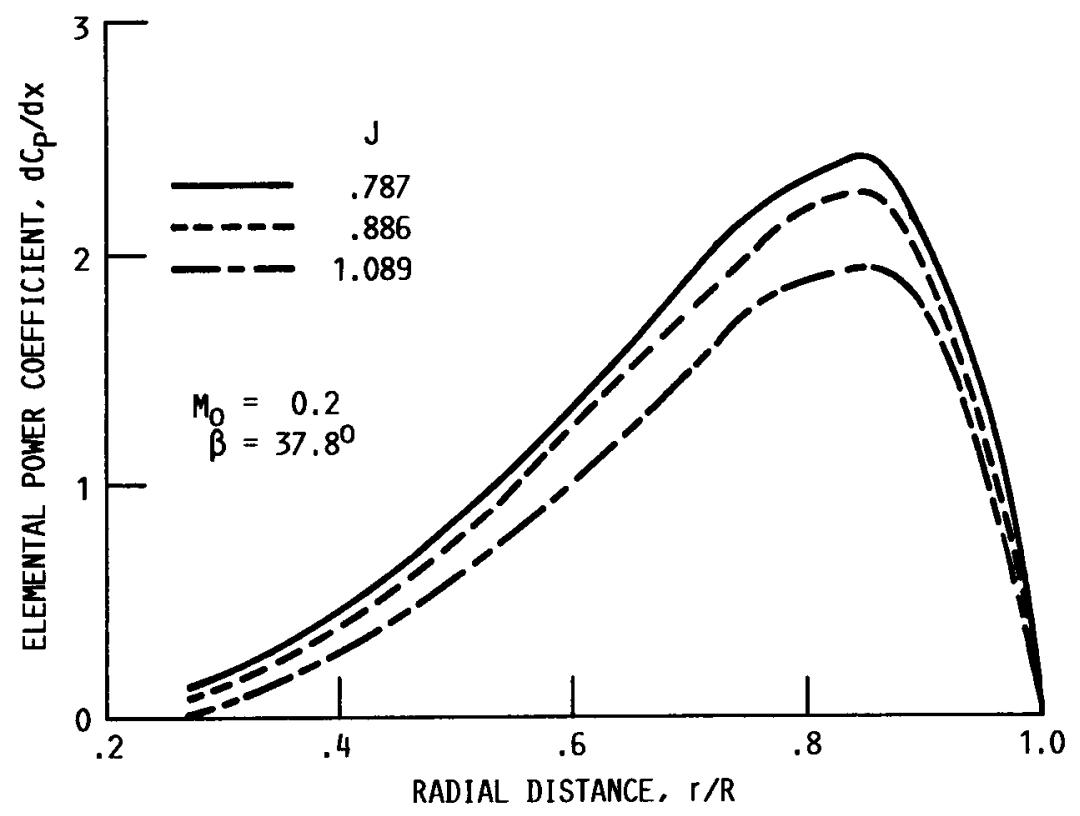

FIGURE 4. - ELEMENTAL POWER COEFFICIENT VARIATION WITH RADIAL DISTANCE AT THREE ADVANCE RATIOS.

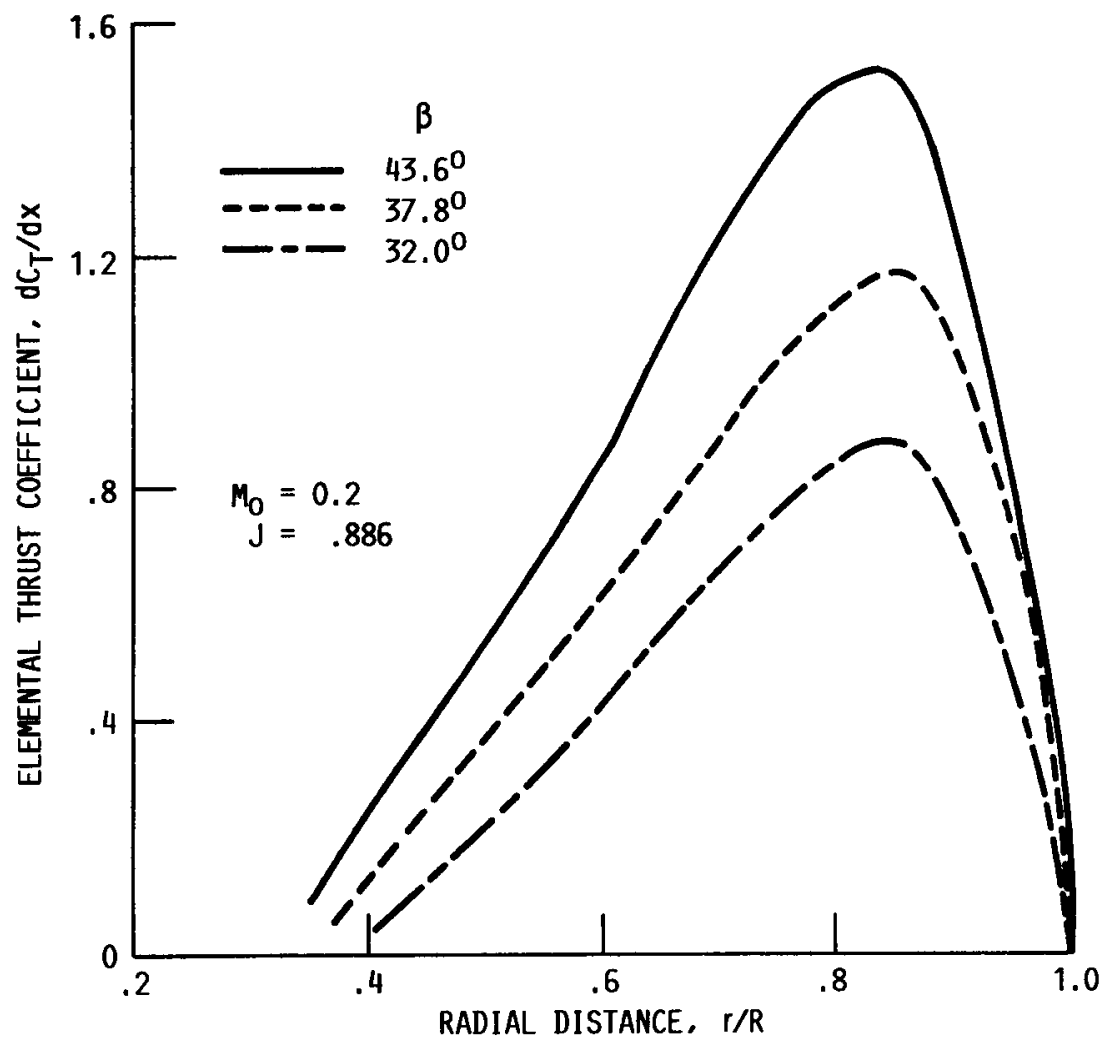

FIGURE 5. - ELEMENTAL THRUST COEFFICIENT VARIATION WITH RADIAL DISTANCE AT THREE BLADE ANGLES. 


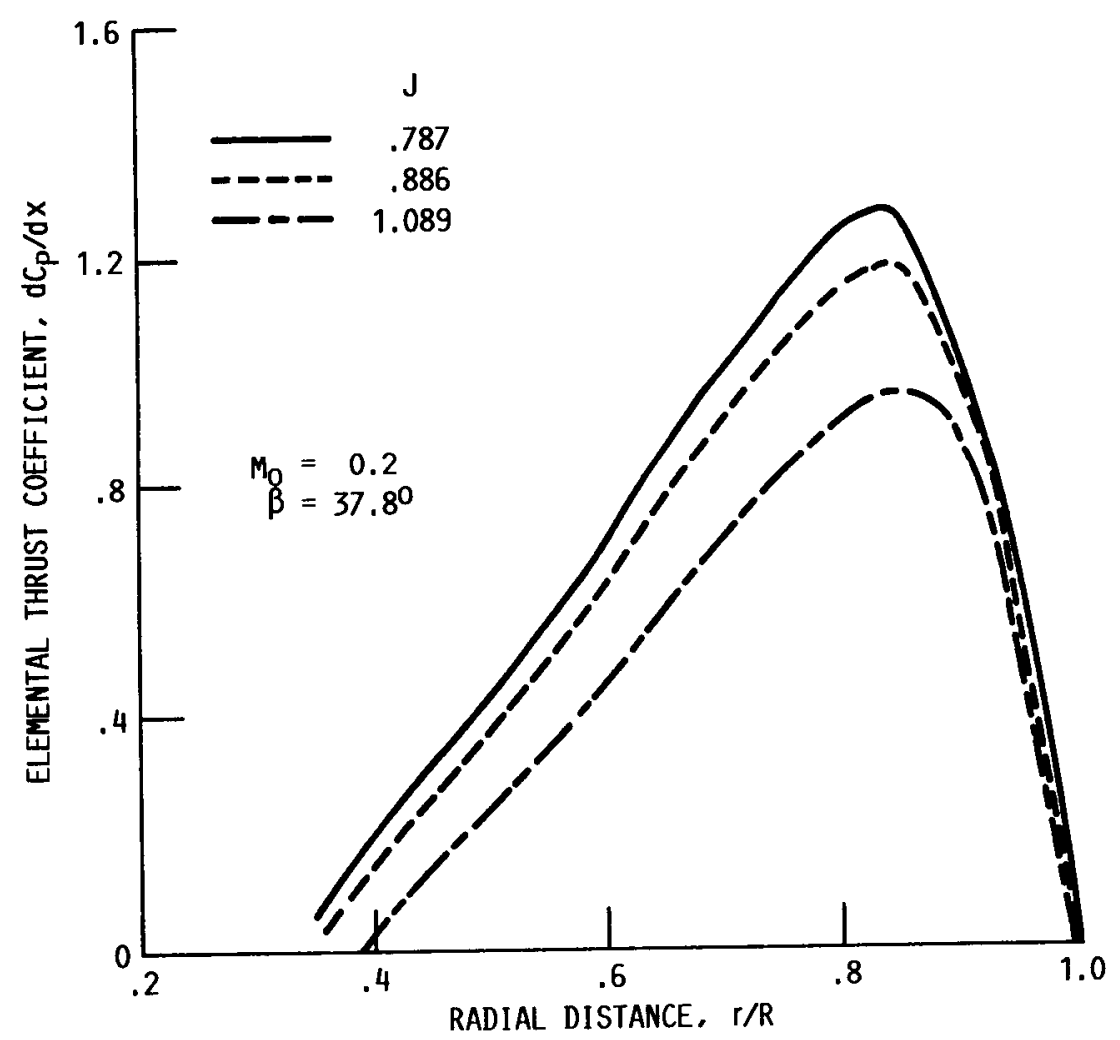

FIGURE 6. - ELEMENTAL THRUST COEFFICIENT VARIATION WITH RADIAL DISTANCE AT THREE ADVANCE RATIOS. 


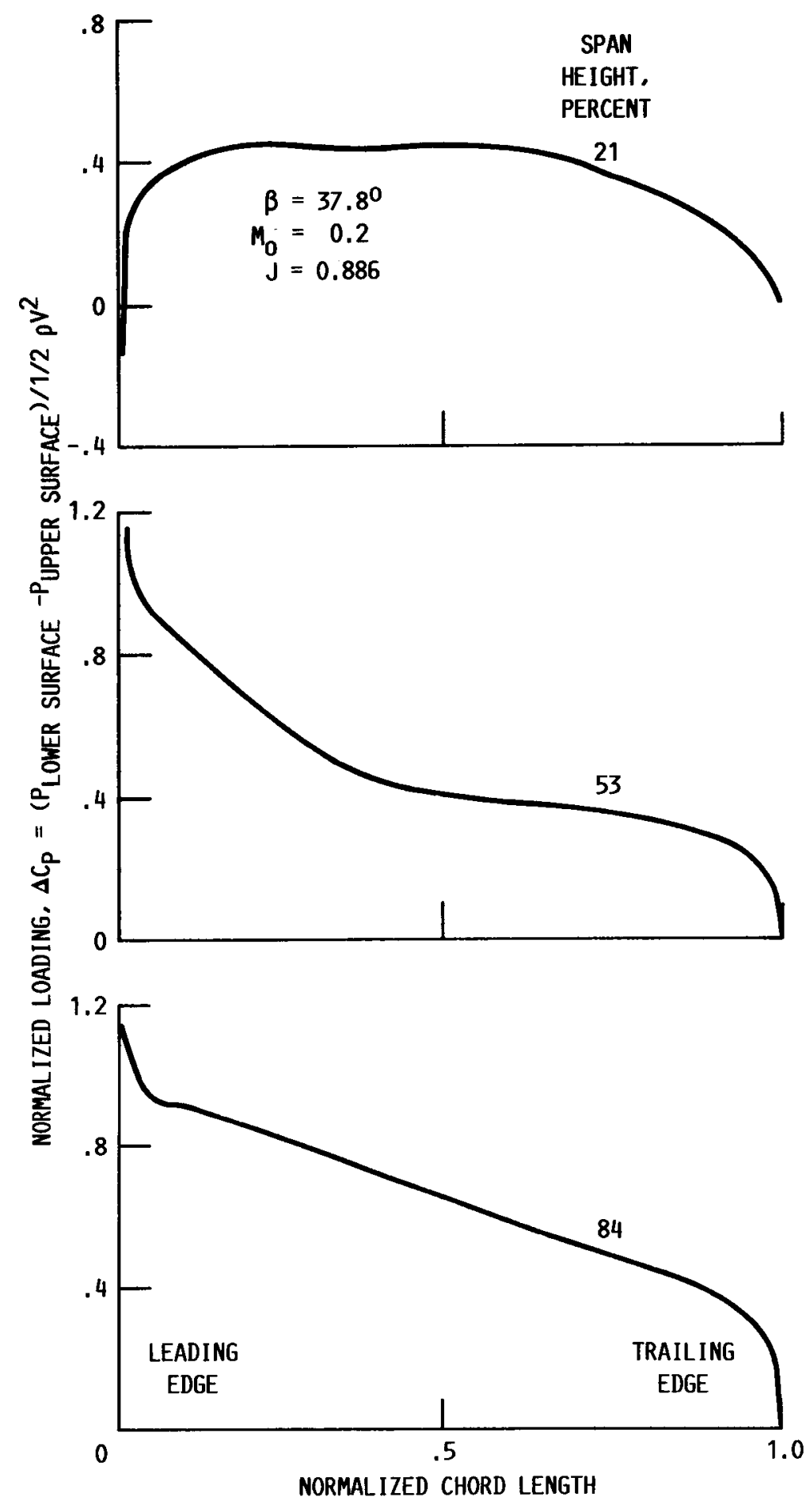

FIGURE 7. - CHORDWISE LOADING DISTRIBUTION. 


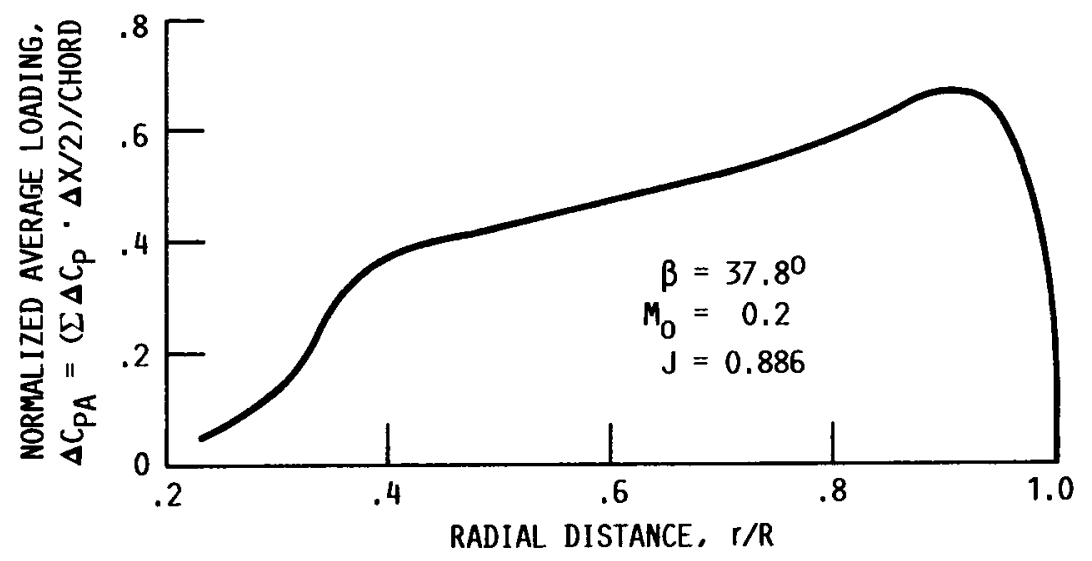

FIGURE 8. - SPANWISE LOADING DISTRIBUTION.

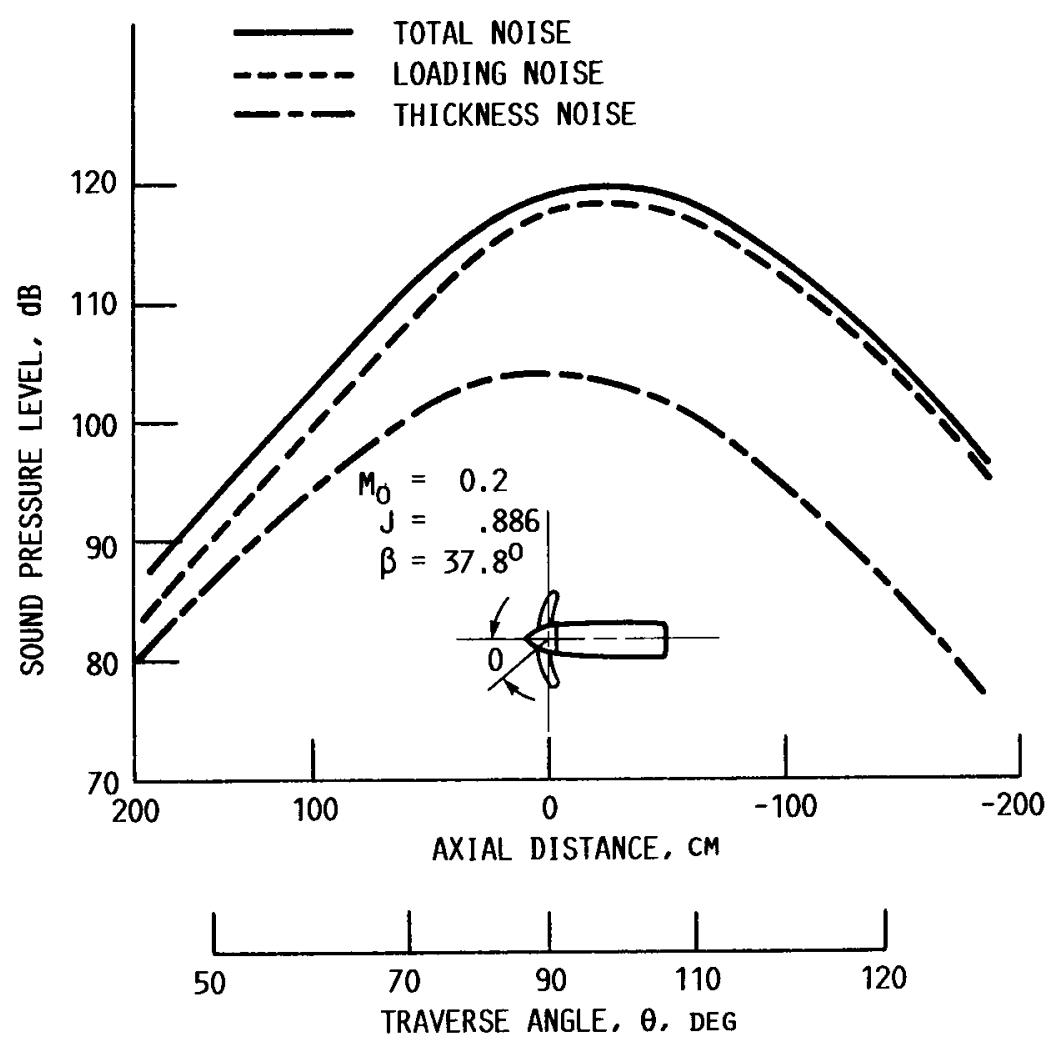

FIGURE 9. - DIRECTIVITIES OF BPF. 

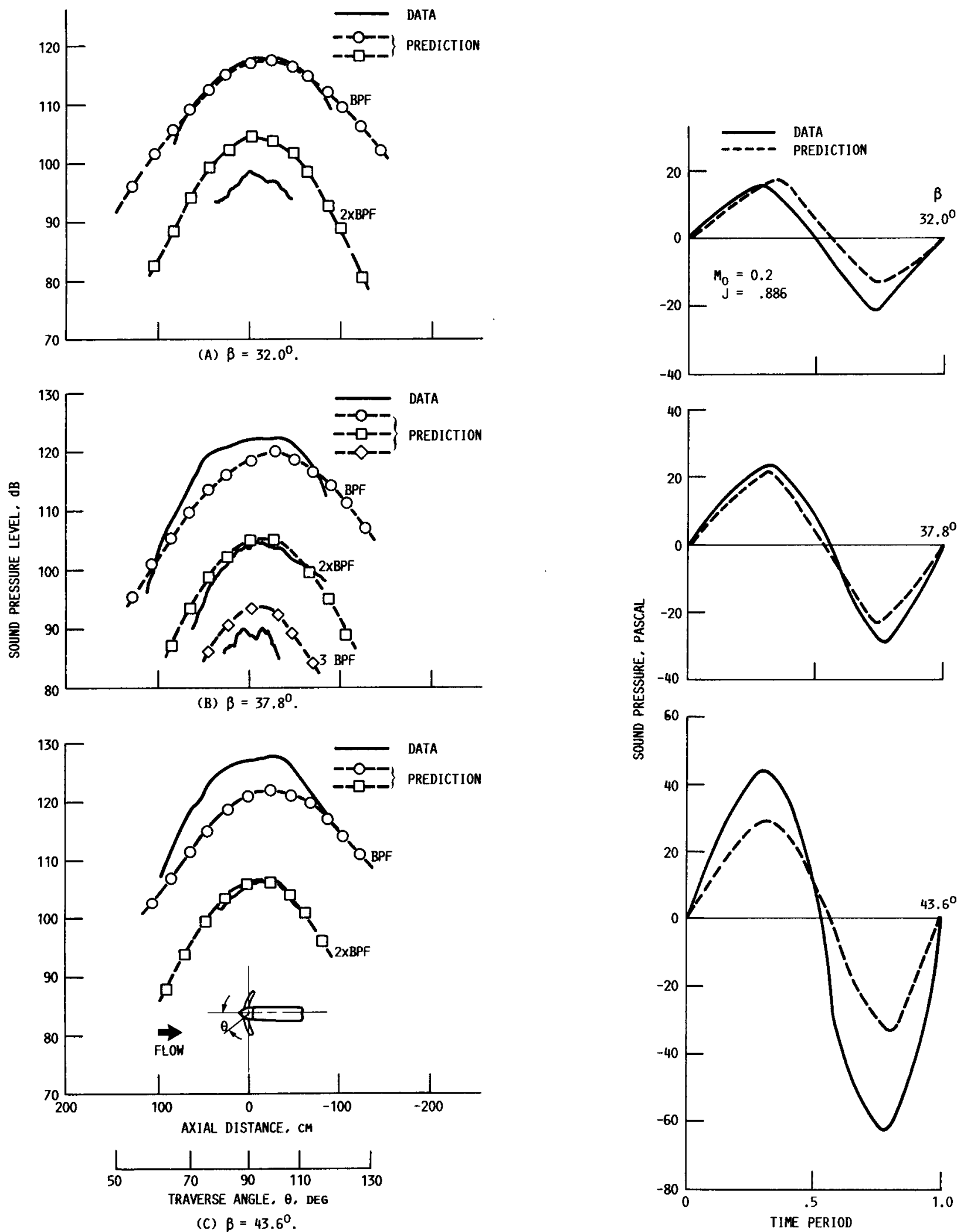

(C) $\beta=43.6^{\circ}$.

FIGURE 10. - COMPARISON OF SR-7A MODEL DATA WITH PREDICTION (1.68 $M$ SIDELINE, $\left.J=0.886, M_{0}=0.2\right)$.

FIGURE 11. - WAVEFORMS IN THE PLANE OF THE PROPELLER AT THREE BLADE ANGLES. 


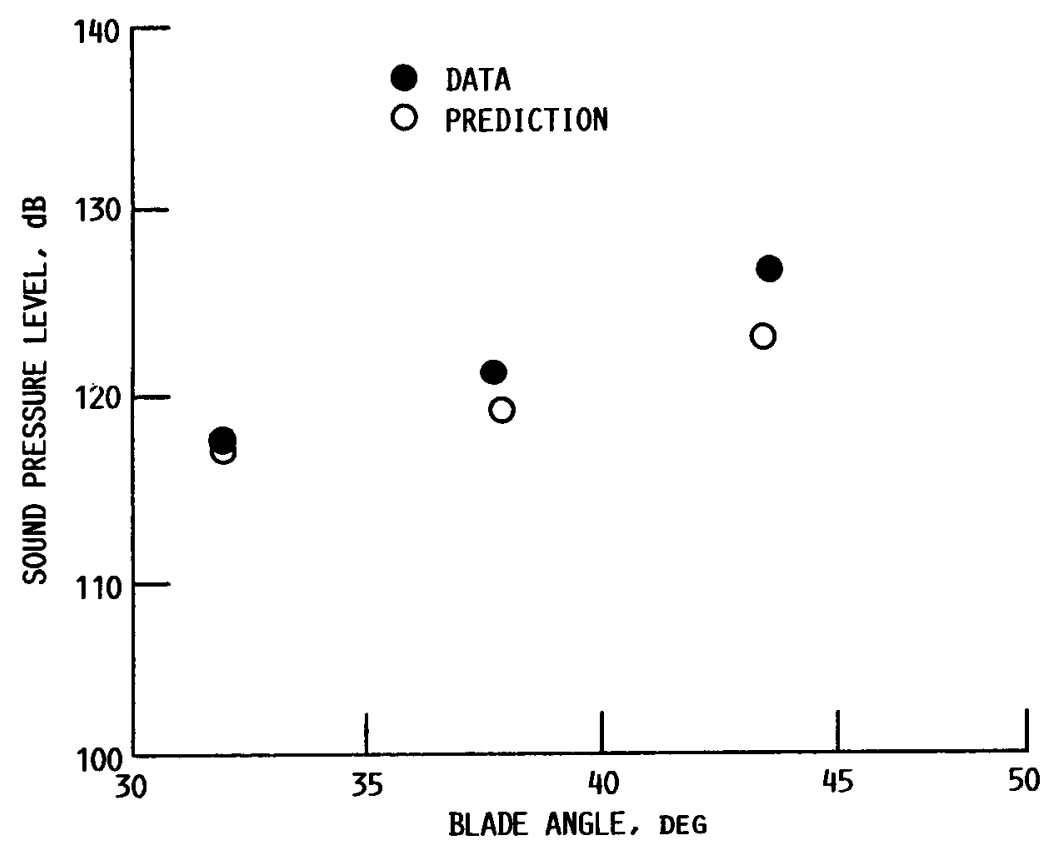

FIGURE 12. - PEAK NOISE LEVELS AS A FUNCTION OF BLADE ANGLE. $\left(M_{0}=0.2, J=0.886\right)$. 

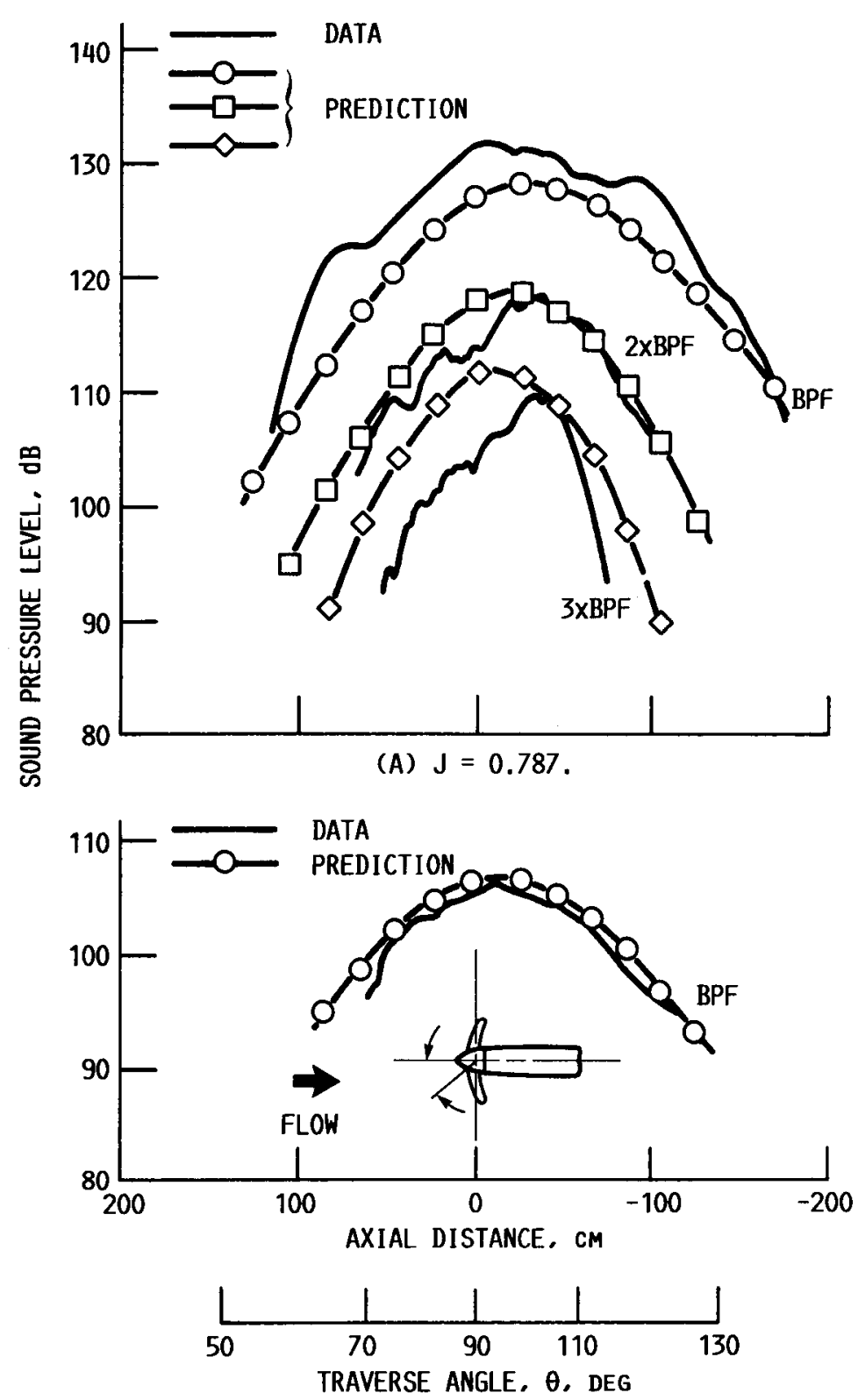

(B) $\mathrm{J}=1.089$.

FIGURE 13. - COMPARISON OF SR-7A MODEL DATA WITH

PREDICTION (1.68 $\mathrm{m}$ SIDELINE, $\left.\beta=37.8^{\circ}, M_{0}=0.2\right)$. 

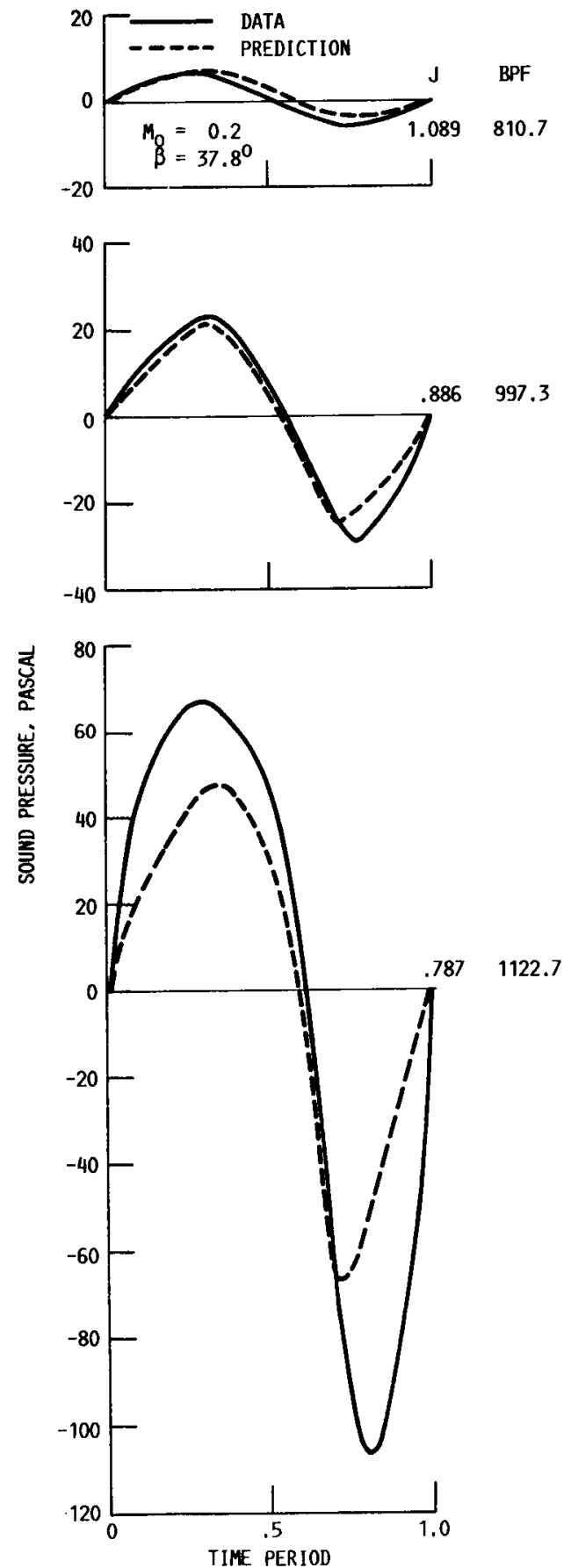

FIGURE 14. - WAVEFORMS IN THE PLANE OF THE PROPELLER AT THREE ADVANCE RATIOS. 


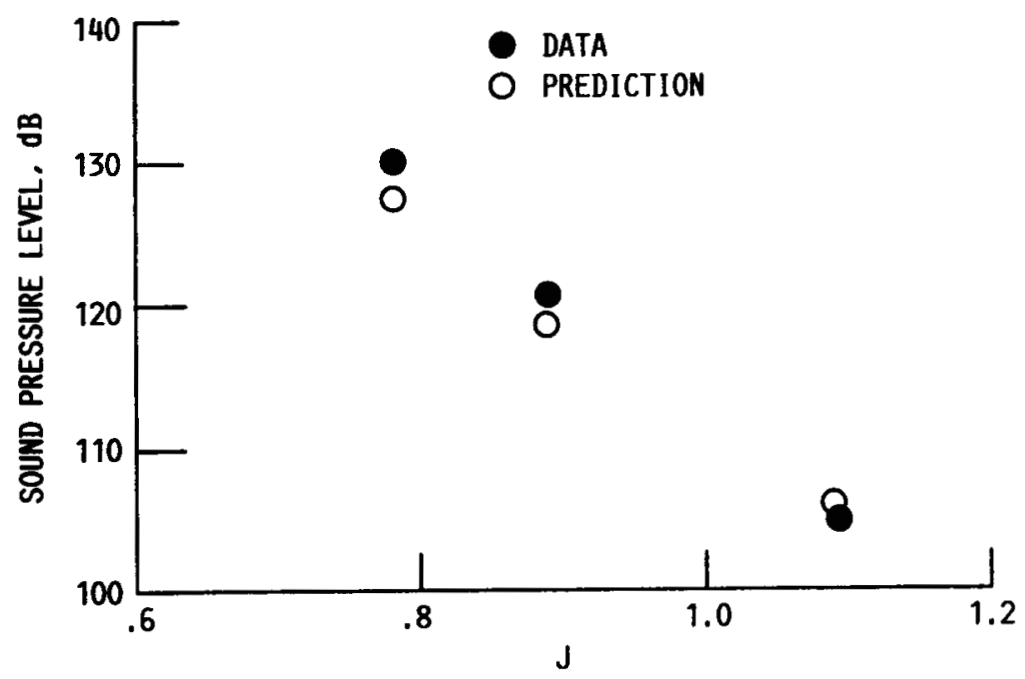

FIGURE 15. - PEAK NOISE LEVELS AS FUNCTION OF ADVANCE RATIO. $\left(M_{0}=0.2, \beta=37.8^{0}\right)$. 


\begin{tabular}{|c|c|c|c|c|}
\hline \multirow{2}{*}{$\begin{array}{l}\text { NSS } \\
\substack{\text { National Aeronautics and } \\
\text { Space Administration }} \\
\text { 1. Report No. } \\
\text { NASA TM-100267 }\end{array}$} & \multicolumn{4}{|c|}{ Report Documentation Page } \\
\hline & \multicolumn{2}{|c|}{ 2. Government Accession No. } & \multicolumn{2}{|c|}{ 3. Recipient's Catalog No. } \\
\hline \multicolumn{3}{|c|}{$\begin{array}{l}\text { High Speed Propeller Performance and Noise } \\
\text { Predictions at Takeoff/Landing Conditions }\end{array}$} & \multicolumn{2}{|l|}{ 5. Report Date } \\
\hline 7. Author(s) & \multicolumn{2}{|c|}{ M. Nallasamy, R.P. Woodward, and J.F. Groeneweg } & \multicolumn{2}{|c|}{$\begin{array}{l}\text { 8. Pertorming Organization Report No. } \\
\text { E-3898 }\end{array}$} \\
\hline 20100 & & 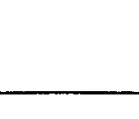 & \multicolumn{2}{|c|}{$\begin{array}{r}\text { 10. Work Unit No. } \\
535-03-01 \\
\end{array}$} \\
\hline \multirow{2}{*}{\multicolumn{3}{|c|}{$\begin{array}{l}\text { National Aeronautics and Space Administration } \\
\text { Lewis Research Center } \\
\text { Cleveland, Ohio } 44135-3191\end{array}$}} & \multicolumn{2}{|c|}{ 11. Contract or Grant No. } \\
\hline & & & \multicolumn{2}{|c|}{ 13. Type of Report and Period Covered } \\
\hline \multicolumn{3}{|c|}{$\begin{array}{l}\text { National Aeronautics and Space Administration } \\
\text { Washington, D.C. } 20546-0001\end{array}$} & \multicolumn{2}{|c|}{ 14. Sponsoring Agency Code } \\
\hline \multicolumn{5}{|c|}{$\begin{array}{l}\text { Prepared for the } 26 \text { th Aerospace Sciences Meeting sponsored by the American } \\
\text { Institute of Aeronautics and Astronautics, Reno, Nevada, January } 11-14,1988 \text {, } \\
\text { M. Nallasamy, Sverdrup Technology, Inc., Lewis Research Center, Cleveland, Ohio } \\
44135 ; \text { R.P. Woodward and J.F. Groeneweg, NASA Lewis Research Center. }\end{array}$} \\
\hline \multicolumn{5}{|c|}{$\begin{array}{l}\text { 16. Abstract } \\
\text { The performance and noise of a high speed SR-7A model propeller under takeoff/ } \\
\text { landing conditions are considered. The blade loading distributions are obtained } \\
\text { by solving the three-dimensional Euler equations and the sound pressure levels } \\
\text { are computed using a time domain approach. At the nominal takeoff operating } \\
\text { point, the blade sections near the hub are lightly or negatively loaded. The } \\
\text { chordwise loading distributions are distinctly different from those of cruise } \\
\text { conditions. The noise of SR-7A model propeller at takeoff is dominated by the } \\
\text { loading noise, similar to that at cruise conditions. The waveforms of the acous- } \\
\text { tic pressure signature are nearly sinusoidal, in the plane of the propeller. The } \\
\text { computed directivity of the blade passing frequency tone agrees fairly well with } \\
\text { the data at nominal takeoff blade angle. }\end{array}$} \\
\hline $\begin{array}{l}\text { 17. Key Words (Suggested by Author } \\
\text { Advanced propel ler } \\
\text { Acoustics; Takeof }\end{array}$ & $\begin{array}{l}\text { dynamics: } \\
\text { ions }\end{array}$ & $\begin{array}{l}\text { 18. Distribe } \\
\text { Uncl } \\
\text { Subj }\end{array}$ & $\begin{array}{l}\text { ent } \\
\text { tegory } 71\end{array}$ & \\
\hline $\begin{array}{l}\text { 19. Security Classif. (of this report) } \\
\text { Unclas s if ied }\end{array}$ & 20. Security Cla & sified & $\begin{array}{c}\text { 21. No of pages } \\
16\end{array}$ & $\begin{array}{r}\text { 22. Price* } \\
\mathrm{AO} 2\end{array}$ \\
\hline
\end{tabular}

